\title{
Carotid Blow-Out Masquerading as Gastrointestinal Hemorrhage: A Case Report
}

\author{
Naga Venkata Krishna Chand Pothineni ${ }^{\mathrm{a}, \mathrm{c}}$, Mohammad Fasihuddin Siddiqui ${ }^{\mathrm{b}}$
}

\begin{abstract}
Tracheo-esophageal prostheses (TEP) are commonly used for speech restoration following laryngectomy for laryngeal cancer. The device is placed through the tracheoesophageal wall into the esophagus superior to the tracheal stoma. We report a case of a ruptured carotid artery presenting as a gastrointestinal bleed. The diagnosis was elusive for a while as initial extensive workup for a source of gastrointestinal bleeding was unsuccessful. To the best of our knowledge, this is the first reported case of a TEP device causing a carotid blow out. This case highlights the importance of looking for atypical sources of bleeding when routine investigations do not provide an etiology.
\end{abstract}

Keywords: Tracheo-esophageal prostheses; Carotid blowout; Gastrointestinal bleed

\section{Introduction}

Tracheo-esophageal prostheses (TEP) are commonly used for speech restoration following laryngectomy for laryngeal cancer. The device is placed through the tracheoesophageal wall into the esophagus superior to the tracheal stoma [1]. The complications from indwelling prostheses are infrequent and include fungal colonization of prosthesis, peri-prosthetic leaks, granulation tissue formation and aspiration of the de-

\footnotetext{
Manuscript accepted for publication February 21, 2013

${ }^{a}$ Department of Internal Medicine, University of Arkansas for Medical Sciences, 4301 W. Markham Street, Slot \# 634, Little Rock, AR, 72205, USA

${ }^{\mathrm{b}}$ Division of Pulmonary and Critical Care, University of Arkansas for Medical Sciences, 4301 W. Markam Street, Slot \# 555, USA

${ }^{\mathrm{c} C}$ Corresponding author: Naga Venkata Krishna Chand Pothineni, Department of Internal Medicine, University of Arkansas for Medical Sciences, 4301 W. Markham Street, Slot \# 634, Little Rock, AR, 72205, USA. Email: NVPothineni@uams.edu
}

doi: http://dx.doi.org/10.4021/jmc1163w vice [2-5]. We report a case of carotid blowout presenting as a gastrointestinal bleed. To the best of our knowledge, this is the first reported case of a TEP device causing a carotid blow out.

\section{Case Report}

A 79-year-old Caucasian male with a history of total laryngectomy for laryngeal cancer presented with an upper gastrointestinal bleed. He had received concomitant radiation therapy, which was complicated by thyroid cancer requiring thyroidectomy. He also developed post radiation esophageal strictures and a percutaneous gastrostomy tube was used for feeding. A tracheoesophageal prosthesis was placed for assistance with speech. He had done well for nearly a decade. During this presentation, work up for gastrointestinal bleed with a limited endoscopy and a tagged red blood cell scan did not reveal an active source of bleeding. Given his history of surgery, a nasopharyngoscopy was performed which was unremarkable. A computerized tomography (CT) scan of the neck was also done which did not show any source of bleeding.

During his hospitalization, he had an episode of massive hemorrhage with blood pouring from this tracheostomy, per-

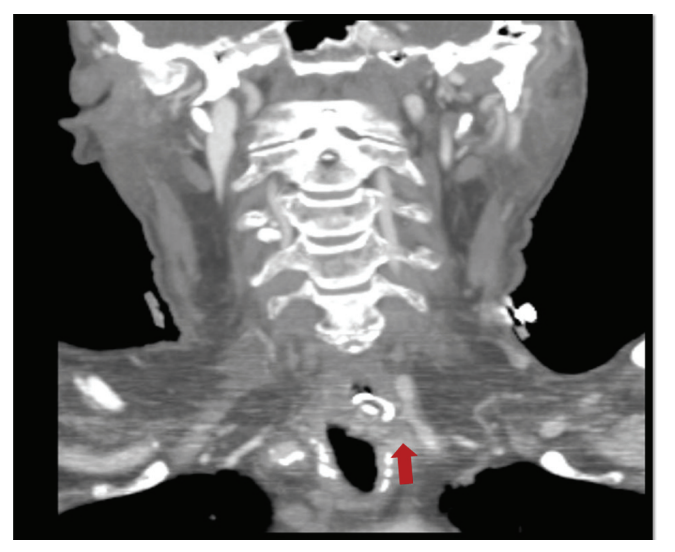

Figure 1. CT neck showing close proximity of the TEP device to the left common carotid. 


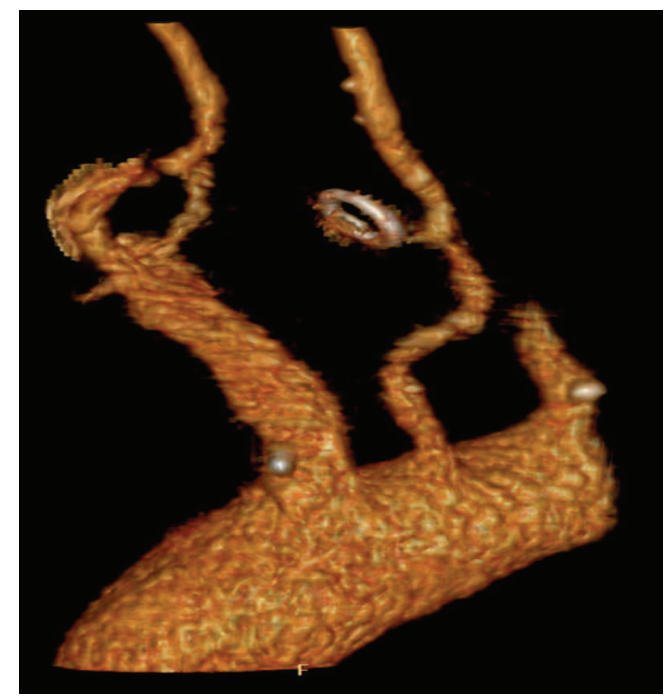

Figure 2. 3D reconstruction showing possible site of bleed from the common carotid into the TEP device.

cutaneous gastrostomy tube and from his mouth. He had a cardiac arrest from hypovolemic shock and was resuscitated with massive transfusions with subsequent return of circulation. An emergent angiography of the neck was performed

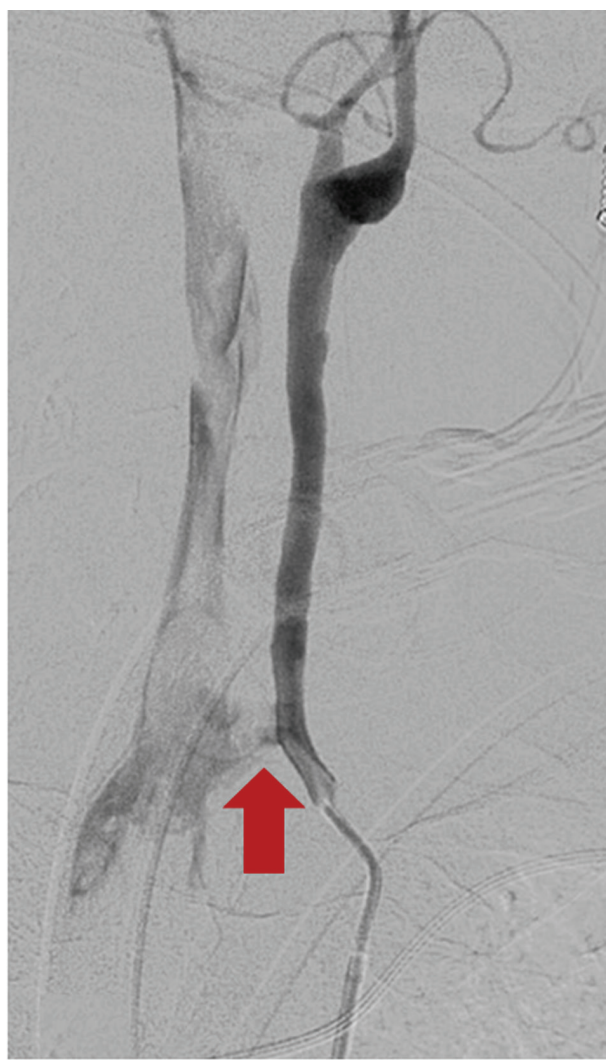

Figure 3. Carotid Angiogram showing oozing of blood into the TEP device.

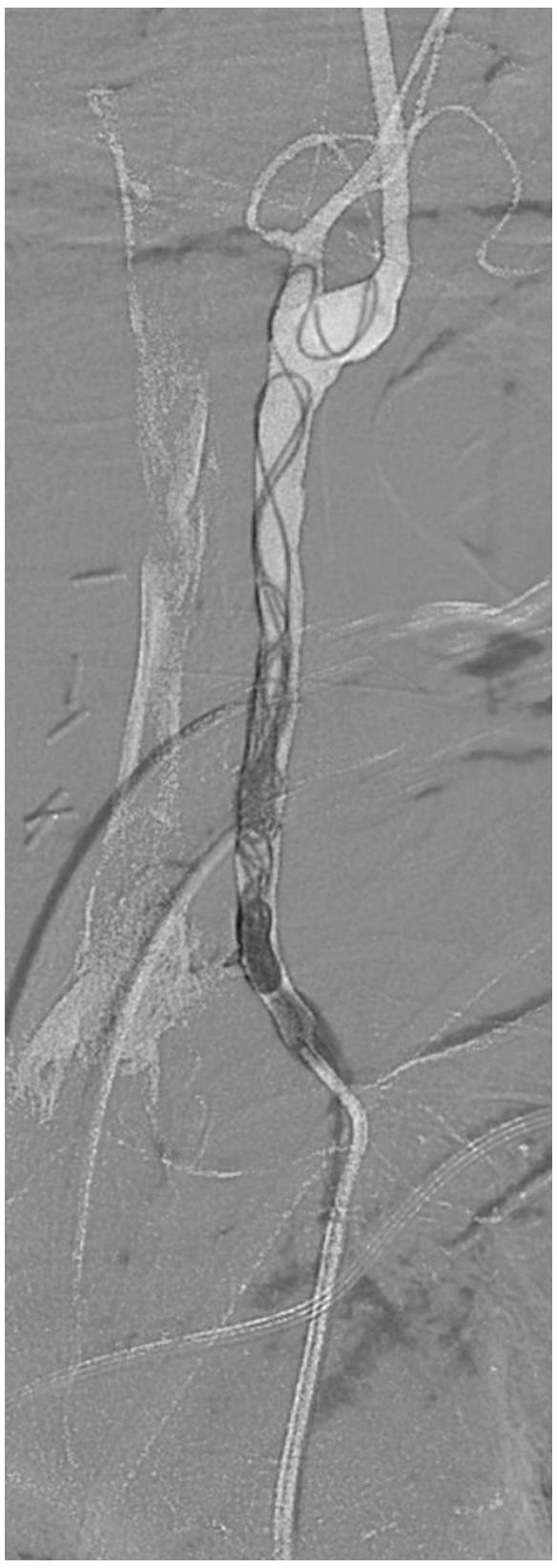

Figure 4. CTA of the left common carotid artery post embolization and coiling showing successful hemostasis.

that identified the bleeding source to be the left common carotid artery at the site of the TEP device. Coiling and gel foam embolization of the left common carotid was able to achieve hemostasis. His hemodynamic status stabilized after the procedure and no further bleeding was noted in the following days. A follow up CT brain following the embolization of the carotid artery did not reveal any areas of cerebral ischemia. On retrospective review of CT scan of the neck, we were able to appreciate the TEP device abutting the wall of the common carotid (Fig. 1,2). This was confirmed by the carotid angiogram which showed active hemorrhage from 
the common carotid (Fig. 3, 4). The patient had irradiation to his neck which predisposed him to the acute blowout of the common carotid. The bleeding from the common carotid artery which was initially sentinel, had found its way into the gastrointestinal tract through the TEP and had presented as a likely gastrointestinal source of bleeding.

\section{Discussion}

Carotid blow-out or carotid artery rupture is a life threatening event with high mortality and morbidity from neurological deficits [6-8]. It is usually seen in patients with malignant tumors of the head and neck, especially after radiation therapy or surgery but is also reported after trauma $[9,10]$. The common carotid artery lies unguarded and very close to the skin and the tracheal stoma following a radical neck dissection, and thyroidectomy [7]. Most episodes are noted within weeks to months following surgery and are thought to be predisposed by local infections [7]. The most common site of carotid blow-out reported is the internal carotid artery followed by the common carotid and external carotid artery [11]. Angiography is the gold standard for establishing diagnosis. Therapy involves either carotid occlusion (by coils or detachable balloons) or endovascular stents [11].

\section{Conclusion}

This case illustrates the importance of looking for a carotid source of hemorrhage in patients with a TEP device and that might present as a gastrointestinal source of bleeding.

\section{Consent Declaration}

Written informed consent was obtained from the patient for publication of this case report and accompanying images. A copy of the written consent is available for review by the Editor-in-Chief of this journal.

\section{Competing Interests}

The authors declare that they have no competing interests.

\section{Authors' Contributions}

NP authored the case presentation part of the manuscript and procured the relevant images. MS authored the discussion part and provided intellectual assistance. All authors read and approved the final manuscript.

\section{Abbreviations}

TEP: Tracheo-esophageal prosthesis; CT: Computerized tomography

\section{References}

1. Blom ED, Singer MI, Hamaker RC. A prospective study of tracheoesophageal speech. Arch Otolaryngol Head Neck Surg. 1986;112(4):440-447.

2. Graville D, Gross N, Andersen P, Everts E, Cohen J. The long-term indwelling tracheoesophageal prosthesis for alaryngeal voice rehabilitation. Arch Otolaryngol Head Neck Surg. 1999;125(3):288-292.

3. Calder N, MacAndie C, MacGregor F. Tracheoesophageal voice prostheses complications in north Glasgow. J Laryngol Otol. 2006;120(6):487-491.

4. Andrews JC, Mickel RA, Hanson DG, Monahan GP, Ward PH. Major complications following tracheoesophageal puncture for voice rehabilitation. Laryngoscope. 1987;97(5):562-567.

5. Pou AM. Tracheoesophageal voice restoration with total laryngectomy. Otolaryngol Clin North Am. 2004;37(3):531-545.

6. Chaloupka JC, Putman CM, Awad IA. Endovascular therapeutic approach to peripheral aneurysms of the superior cerebellar artery. AJNR Am J Neuroradiol. 1996;17(7):1338-1342.

7. Upile T, Triaridis S, Kirkland P, Archer D, Searle A, Irving $C$, Rhys Evans P. The management of carotid artery rupture. Eur Arch Otorhinolaryngol. 2005;262(7):555560.

8. Hillerman BL, Kennedy TL. Carotid rupture and tissue coverage. Laryngoscope. 1982;92(9 Pt 1):985-988.

9. Chang FC, Lirng JF, Luo CB, Wang SJ, Wu HM, Guo WY, Teng MM, et al. Patients with head and neck cancers and associated postirradiated carotid blowout syndrome: endovascular therapeutic methods and outcomes. J Vasc Surg. 2008;47(5):936-945.

10. Maron BJ, Poliac LC, Ashare AB, Hall WA. Sudden death due to neck blows among amateur hockey players. JAMA. 2003;290(5):599-601.

11. Cohen J, Rad I. Contemporary management of carotid blowout. Curr Opin Otolaryngol Head Neck Surg. 2004;12(2):110-115. 